\title{
Pengaruh Implementasi Metode Safety Talk dan Check pada Petani Hortikultura di Desa Sumber Mufakat Kabupaten Karo
}

\author{
Eka Lestari Mahyuni ${ }^{1}$, Ida Yustina ${ }^{2}$, Etty Sudaryati ${ }^{3}$ \\ Departemen Keselamatan dan Kesehatan Kerja, Fakultas Kesehatan Masyarakat, Universitas Sumatera Utara \\ Jl. Universitas No 21 Kampus USU, Medan 20155 \\ 1eka_mahyuni@ymail.com \\ 2ida_yust@yahoo.com \\ 3etysudaryati@gmail.com
}

\begin{abstract}
ABSTRAK
Petani hortikultura merupakan petani yang menggunakan pestisida dalam jumlah dan frekuensi yang tinggi sesuai dengan pola tanaman yang diproduksi. Dalam penggunaannya, petani hortikultura di desa Sumber Mufakat tidak menggunakan pelindung diri sehingga kontak langsung ataupun paparan lingkungan kerap terjadi selama menggunakan pestisida. Tujuan penelitian ini adalah untuk mengetahui pengaruh implementasi metode safety talk dan check pada petani sebagai satu langkah preventif dalam menciptakan pola penggunaan pestisida yang aman dan sehat. Penelitian ini merupakan penelitian survey intervensi dengan menggunakan metode gabungan. Desain kualitatif menggunakan pendekatan Participatory Action Research (PAR) dan secara kuantitatif menggunakan quasi eksperimen. Partisipan diambil dari 9 kelompok tani sebanyak 35 orang dan mengimplementasikan pada 100 petani di desa Sumber Mufakat. Data yang diperoleh dianalisis secara deskriptif. Hasil penelitian berdasarkan wawancara subjektif pada petani menunjukkan bahwa pelaksanaan metode safety talk dapat dilaksanakan secara menyeluruh namun kendala yang dihadapi adalah rasa ketidakpedulian masyarakat dan faktor lupa yang sering menjadi alasan. Safety talk memiliki pengaruh yang signifikan dalam meningkatkan awareness masyarakat ( -value=0,0001; OR=3,958). Penerapan metode check dapat dilakukan dengan baik, namun petani masih merasa belum memahami dengan jelas gejala yang dirasakan. Variabel yang berpengaruh penerapan check adalah tingkat pengetahuan ( -value $=0,032$; $\mathrm{OR}=2,11)$. Berdasarkan hasil penelitian, metode safety talk dan check dapat berjalan sebagaimana mestinya dengan didukung adanya informasi-informasi yang terkait secara terus menerus dan dukungan dari instansi pemerintahan. Direkomendasikan metode safety talk dan check dapat dijadikan satu kebijakan kesehatan dan disosialisasikan secara komprehensif.
\end{abstract}

Kata kunci: Petani hortikultura, Pestisida, Metode, Safety Talk, Check

\begin{abstract}
Horticultural farmers always use pesticides in high quantities and frequencies in accordance with the pattern of plants produced. In its use, horticultural farmers in Sumber Mufakat village didn't use personal protection, so direct contact or environmental exposure often occurs during they use of pesticides. The purpose of this research was to determine the effect of the implementation of safety talk and check method for farmers as a preventive step in creating a safety and health pesticide use pattern. This research is an intervention survey research in mixed method. The qualitative design use Participatory Action Research (PAR) approach ang quantitative uses quasi experiment. There are 35 participant collect from nine groups and implement the method to 100 farmers as sample. Data obtained were analyzed in descriptively. The result based on subjective interviews showed in the implementation of safety talk can be carried out thoroughly but the farmers argue that the obstacle faced was a sense of community indifference and forgetful factors that are often the reason. Safety talk has a significant influence in increasing farmers awareness ( $p$-value $=0,0001 ;$ OR $=3,958)$. The application of the check method can be done well, but farmers still feel not clearly understood the symptoms. The variables that influence the application of check are the level of knowledge ( $p$-value $=0.032 ;$ OR $=2.11$ ). Based on the results, safety talk and check method can run properly with the support of continuous related information and support from government institution. Recommended methods of safety talk and check can be a comprehensive health policy and socialized.
\end{abstract}

Keywords: Horticultural Farmers, Pesticides, Method, Safety Talk, Check 


\section{Pendahuluan}

Keselamatan dan Kesehatan Kerja (K3) adalah salah satu ilmu terapan yang berperan besar dalam melindungi pekerja di tempat kerja baik di darat, air maupun udara. Keselamatan kerja merupakan sarana utama untuk mencegah terjadinya kecelakaan kerja yang dapat menimbulkan kerugian berupa luka/cidera, cacat atau kematian, kerugian harta benda dan kerusakan peralatan/mesin dan lingkungan secara luas. Kesehatan Kerja atau dalam bahasa asing disebut sebagai Occupational Health adalah tools yang komprehensif untuk memecahkan masalah penyakit akibat kerja (PAK). PAK dapat dikendalikan dengan serangkaian upaya kesehatan kerja mulai dari promotif, preventif, kuratif dan rehabilitatif, mencakup upaya medis, teknis, administratif dan melibatkan profesional multidisiplin lainnya[1,2,3].

Indonesia, sebagai negara agraris didominasi dengan banyaknya masyarakat yang bergerak di bidang pertanian dan perkebunan. Potensi risiko yang tinggi di lingkungan kerja petani adalah penggunaan bahan kimia yaitu pupuk dan pestisida. Sebagai bahan kimia, pestisida memberi dampak bagi petani berupa paparan dan kemungkinan keracunan bahan kimia yang terdapat dalam kandungan pestisida [4].

Berdasarkan aspek keselamatan dan kesehatan kerja, menggunakan pestisida yang tidak sesuai prosedur merupakan salah satu faktor bahaya yang dapat menimbulkan kecelakaan atau PAK seperti keracunan. Keracunan yang paling berisiko dari penggunaan pestisida yang salah ditandai dengan kadar aktivitas enzim cholinesterase dalam darah. Gejala keracunan yang dialami dapat diawali dengan pusing, sakit kepala, iritasi dan akhirnya dapat memicu ke arah kanker [5,6,7].

Desa Sumber Mufakat merupakan salah satu desa yang ada di Kecamatan Kabanjahe Kabupaten Karo yang mayoritas penduduknya bekerja sebagai petani yang bergerak di bidang hortikultura. Tanaman yang diolah oleh petani meliputi tomat, cabai, kembang kol, brokoli, buncis, sawi dan bunga. Dalam kesehariannya petani selalu terpapar dengan pestisida karena tidak digunakannya pelindung diri selama menggunakan pestisida, sehingga kontak langsung kerap terjadi. Petani juga mengalami gejala keracunan seperti pusing, sakit kepala, diare, mata memerah, kulit panas akibat menggunakan pestisida [8].

Berdasarkan gejala dan pola penggunaan pestisida yang tidak aman dan sehat tersebut, maka tujuan penelitian ini adalah untuk mengetahui pengaruh implementasi metode safety talk dan check pada petani sebagai satu langkah preventif dalam menciptakan pola penggunaan pestisida yang aman dan sehat.

\section{Metode Penelitian}

Penelitian ini merupakan penelitian survey intervensi dengan menggunakan metode gabungan (mixed method). Desain kualitatif menggunakan pendekatan Participatory Action Research (PAR). Desain kuantitatif bersifat cross sectional dan menggunakan pendekatan quasi eksperiment. Data dikumpulkan melalui observasi dan menggunakan instrumen kuesioner. Populasi penelitian adalah seluruh petani yang terdaftar dalam kelompok tani yang ada di desa Sumber Mufakat. Teknik pengambilan sampel dilakukan dengan cara proportional probability sampling [9].

Implementasi safety talk dan check dilakukan dengan pengkaderan beberapa perwakilan yang diambil dari 9 kelompok tani yang ada di desa Sumber Mufakat sejumlah 35 orang. Tiap kader dilatih dan menerapkan metode safety talk dan check pada tiap anggota kelompok taninya yang diambil sebanyak 100 orang sesuai proporsi tiap kelompok tani. Hasil penelitian akan dianalisis secara deskriptif.

\section{Hasil dan Pembahasan}

Desa Sumber Mufakat merupakan salah satu desa terkecil yang ada di Kecamatan Kabanjahe. Rata-rata masyarakat di Desa Sumber Mufakat ini bekerja di bidang pertanian dimana lahan pertanian tersebut banyak dilakukan di samping rumah, belakang rumah atau lahan terbuka yang merupakan areal pertanian yang dikelola sendiri oleh masyarakat. Lahan yang dikelola oleh masyarakat mayoritas ditanami dengan tanaman holtikultura seperti cabe, tomat, labu, kentang, terong dan sebagainya.

Penerapan metode safety talk dan check pada petani di Desa Sumber Mufakat Kabupaten Kabanjahe diawali dengan melakukan pemilihan kader petani. Kader dipilih sebagai agent untuk menerapkan metode safety talk dan check. Dari 321 anggota kelompok tani dipilih sebanyak 35 kader dari 9 kelompok tani yang ada di desa Sumber Mufakat. (Tabel 1). Kader yang dipilih diberi pelatihan tentang metode safety talk dan check dalam penggunaan pestisida. Setiap kader akan mengimplementasikan metode safety talk dan check pada rekan petani yang ada di Sumber Mufakat. Pola yang digunakan petani adalah dengan mengunjungi ladang-ladang dan mengobservasi langsung rekan-rekan petani selama menggunakan pestisida. Pada saat yang bersamaan kader akan menyampaikan pesan keselamatan apabila tindakan yang dilakukan tidak sesuai dengan ketentuan yang ditetapkan. Di samping itu kader juga melakukan wawancara mengenai keluhan kesehatan yang dirasakan selama menggunakan pestisida dengan mengisi lembar check yang disediakan. 
Tabel 1. Kader petani yang menerapkan metode Safety Talk dan Check

\begin{tabular}{cccccccccc}
\hline & \multicolumn{10}{c}{ Nama Kelompok Tani } \\
\cline { 2 - 10 } & $\begin{array}{c}\text { Rejeki } \\
\text { Tani }\end{array}$ & $\begin{array}{c}\text { Tambar } \\
\text { Malem }\end{array}$ & $\begin{array}{c}\text { Rabu II } \\
\text { Pasar }\end{array}$ & $\begin{array}{c}\text { Arih } \\
\text { Ersada I }\end{array}$ & $\begin{array}{c}\text { Arih } \\
\text { Ersada II }\end{array}$ & $\begin{array}{c}\text { Juma } \\
\text { Barung }\end{array}$ & $\begin{array}{c}\text { Dalan } \\
\text { Kutiga I }\end{array}$ & $\begin{array}{c}\text { Dalan } \\
\text { Kutiga II }\end{array}$ & $\begin{array}{c}\text { Bunga } \\
\text { Sumbul }\end{array}$ \\
\cline { 2 - 10 } Jumlah & 27 & 35 & 47 & 65 & 46 & 22 & 32 & 31 & 16 \\
$\begin{array}{c}\text { Anggota } \\
\text { Kader yang } \\
\text { dipilih }\end{array}$ & 3 & 4 & 5 & 7 & 5 & 3 & 3 & 3 & 3 \\
\hline
\end{tabular}

Kader yang dipilih mengimplementasikan metode safety talk dan check pada tiap petani yang ada di kelompok tani secara langsung. Beberapa hal yang ditemukan diantaranya perilaku merokok, melawan arah angin, tidak menggunakan APD, dan sikap yang tidak ergonomis (Tabel 2). Ketidakergonomisan terlihat dari sikap kerja yang mengharuskan membungkuk dan jongkok dalam waktu yang lama sehingga sering menimbulkan rasa sakit pada pinggang, kaki, bahu dan pinggang. Petani juga sering mengalami kelelahan setelah melakukan aktivitas berladang. Kelelahan yang dialami diantaranya karena aktivitas berladang/bertani mengharuskan petani terpapar dengan cuaca dan berjalan cukup lama sesuai dengan luas ladang/lahan pertanian yang dikelola.

Tabel 2. Gambaran penerapan safety talk dan check pada petani di Sumber Mufakat

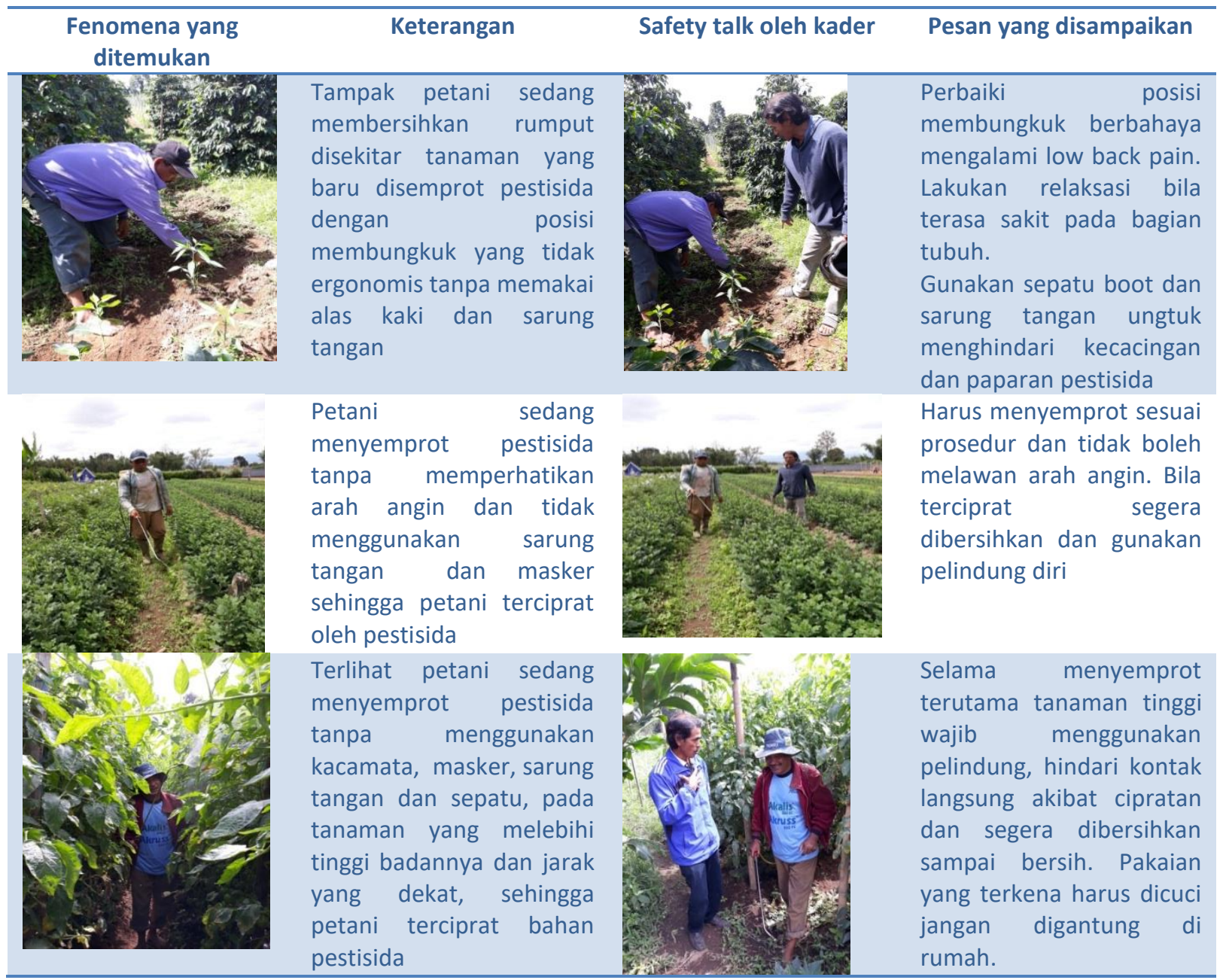




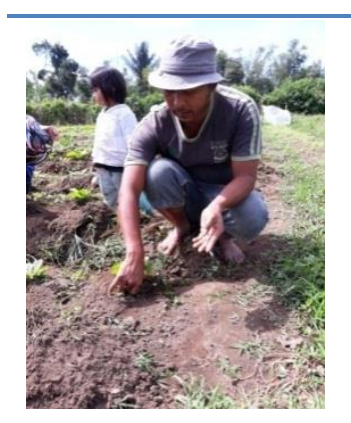

$\begin{array}{lr}\text { Petani } & \text { sedang } \\ \text { membersihkan } & \text { rumput } \\ \text { liar disekitar } & \text { area } \\ \text { tanaman yang disemprot } & \text { tanpa } \\ \text { pestisida } & \text { sarung } \\ \text { menggunakan } & \text { diarea } \\ \text { tangan dan alas } & \text { kaki dan } \\ \text { terlihat } & \text { perkebunan tersebut anak } \\ \text { dari petani bermain main } \\ \text { tanpa menggunakan alas } \\ \text { kaki }\end{array}$

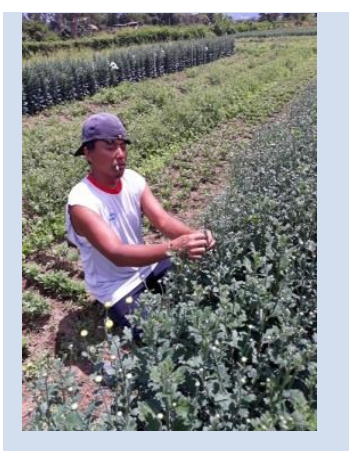

Petani sedang menyiangi tanaman yang sehari sebelumnya disemprot pestisida sambil merokok tanpa menggunakan masker dan sarung tangan dengan posisi kerja yang kurang baik yaitu bersimpuh di tanah.

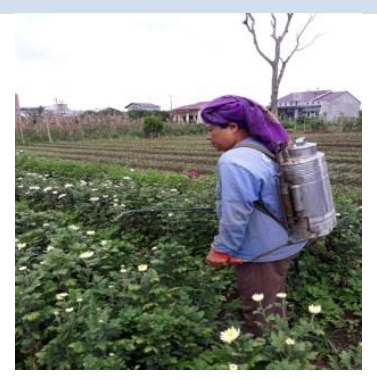

Terlihat sedang melakukan penyemprotan tanpa memakai sarung tangan dan sepatu serta alat semprot yang digunakan memiliki kebocoran sehingga petani terkena pestisida

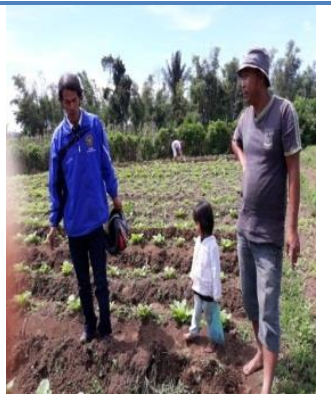

Gunakan sarung tangan dan sepatu boot untuk mencegah kecacingan dan mencuci tangan dengan bersih menggunakan sabun.

Tidak boleh membiarkan anak bermain karena rentan terhadap paparan pestsida yang disemprotkan di tanah.

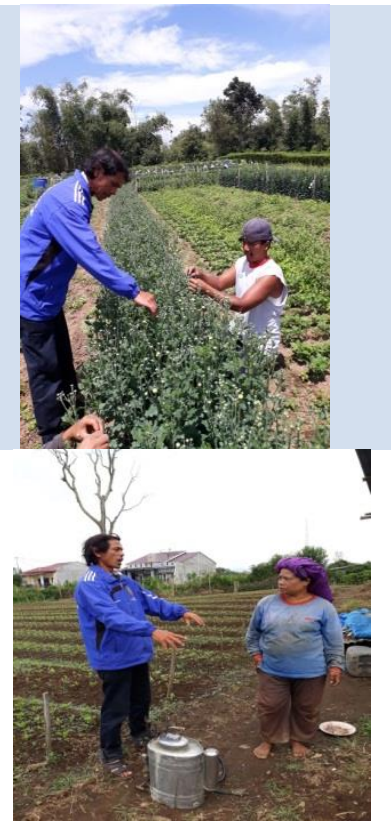

Memegang sisa pestilsida dan sambil merokok dapat terpapar pestisida lewat kulit melalui tangan dan dapat tertelan dan terhirup bersama rokok yang dihisap. Biasakan tidak merokok dan pelindung sarung tangan dan masker.

Disarankan kepada petani untuk memperhatikan keamanan alat yang digunakan. Bila bocor gunakan pelindung agar rembesan tidak langsung kena ke pakaian, dan pompa yang bocor segera diperbaiki.

\section{Sumber : Data penelitian terapan, 2017}

Berdasarkan penerapan safety talk, kader menemukan fenomena yang cukup homogen di ladang seperti petani yang tidak menggunakan pelindung diri, hanya menggunakan pakaian dan jaket serta topi. Tidak semua petani menggunakan sepatu dan menyemprot pestisida tanpa memperhatikan arah angin. Petani juga banyak mengalami posisi statis seperti membungkuk sambil menyiangi rumput, jongkok dan menunduk. Pesan keselamatan (safety talk) yang disampaikan oleh kader berdasarkan fenomena yang ditemui di lapangan diantaranya mengingatkan petani hortikultura untuk menggunakan pelindung diri seperti masker, sarung tangan, topi dan sepatu boot. Kader juga mengingatkan dan menyarankan petani untuk melakukan relaksasi selama 3-5 menit apabila terlalu lama membungkuk, jongkok, dan menunduk. Kader juga melihat fenomena petani terpercik dan terkena pestisida langsung dan menyarankan untuk segera dicuci dengan air bersih dan sabun. Namun dalam pelaksanaannya setiap pesan masih diterima dan tidak dapat dilakukan secara langsung karena beberapa alasan seperti lupa membawa pelindung diri, tidak memiliki pelindung diri, tidak tahu, tidak ada air bersih di ladang, dan sebagainya.

Penerapan metode check, kader merumuskan bahwa gejala yang sering dirasakan petani diantaranya sakit kepala, kembung, mata merah, kulit tangan panas dan terbakar, lelah, diare dan keringat dingin. Dari gejala yang dialami memiliki frekuensi yang cukup sering dan menjadi keluhan yang dianggap biasa oleh petani karena hampir dirasakan setiap hari. Berdasarkan hasil implementasi metode ini penerapan safety talk memiliki pengaruh yang signifikan dalam meningkatkan awareness masyarakat ( $p$-value $=0,0001 ; \mathrm{OR}=3,958$ ). Baik petani maupun kader merasa sadar bahwa selama ini mengabaikan keamanan dan kesehatan selama menggunakan pestisida. Petani baru mengetahui bahwa melawan arah angin membuat paparan langsung dengan pestisida dimana sering dialami terpercik pestisida pada bagian mata dan wajah. Petani juga menyadari perlunya pengawasan dan perhatian agar keamanan dan kesehatan dalam penggunaan pestisida perlu dibenahi.

Hasil wawancara subjektif pada petani menunjukkan bahwa dalam pelaksanaan metode safety talk dapat dilaksanakan secara menyeluruh namun petani berpendapat kendala yang dihadapi adalah rasa 
ketidakpedulian masyarakat dan faktor lupa yang sering menjadi alasan. Masyarakat juga memahami keracunan namun merasa cukup sulit dalam meningkatkan pola penggunaan pestisida yang aman dan sehat.

Penerapan metode check dapat dilakukan dengan baik, namun petani masih merasa belum memahami dengan jelas gejala yang dirasakan karena pestisida yang digunakan dapat hilang bila dibersihkan atau dengan memakan sirih, walaupun akan tetap muncul selama menggunakan pestisida. Gejala kesehatan yang dirasakan juga sudah dianggap biasa karena selalu dirasakan setiap hari. Petani pada awalnya tidak mengetahui bahwa gejala tersebut merupakan gejala keracunan yang perlu diwaspadai dan diperhatikan untuk menghindari dampak keracunan akibat penggunaan pestisida. Berdasarkan uji statistik yang dilakukan, variabel yang berpengaruh penerapan check adalah tingkat pengetahuan petani ( $p$-value $=0,032 ; \mathrm{OR}=2,11$ ).

Berdasarkan hasil penelitian yang diperoleh pesan safety talk yang disampaikan kader didominasi dengan anjuran menggunakan alat pelindung diri selama menggunakan pestisida. Hal ini merupakan hal yang mendasar dimana tidak digunakannya pelindung diri akan berpotensi mengalami kontak langsung yang berisiko bagi keselamatan dan kesehatan petani. Risiko terpercik, tertumpah, tertelan dapat terjadi mulai dari proses pencampuran, pengangkatan pompa semprot dan penyemprotan pestisida dan kontak langsung dialami petani akibat tidak digunakannya pelindung diri. Hal ini dapat meningkatkan aktivitas enzym cholinesterase yang merupakan indikator keracunan pestisida secara signifikan [10].

Dalam proses kerja petani hortikulktura sering menunjukkan sikap tubuh yang statis, repetitif dan tidak ergonomis. Akibatnya kelelahan dirasakan dengan gejala sesak nafas dan lemah. Petani juga merasakan nyeri punggung bawah (NPB) akibat posisi statis. Posisi kerja yang statis (durasi lama) merupakan faktor risiko terjadinya keluhan musculoskeletal dan nyeri punggung bawah [11]. Dalam mengurangi gejala tersebut, kader menganjurkan untuk melakukan relaksasi untuk memperlancar aliran darah dalam tubuh.

Gejala kesehatan yang timbul akibat penggunaan pestisida menunjukkan keracunan yang bersifat kronis. Menurut Pandit, tingkat keracunan pestisida jenis insektisida dapat dibedakan menjadi 3, yaitu acute poisoning, yaitu keracunan yang terjadi akibat masuknya sejumlah besar pestisida sekaligus ke dalam tubuh. Misal, kasus salah makan ataupun bunuh diri. Gejala dari keracunan akut, mual, muntah-muntah, sakit kepala, pusing, panik, kejang otot, dan lemah otot. Sub acut poisoning, merupakan keracunan yang ditimbulkan oleh sejumlah kecil pestisida yang masuk ke dalam tubuh, namun terjadinya secara berulang-ulang. Sementara untuk chronic poisoning, yaitu keracunan akibat masuknya sejumlah kecil pestisida dalam waktu yang lama dan pestisida mengalami kecenderungan untuk terakumulasi dalam tubuh [12]. Keracunan akut berat menimbulkan gejala mual, menggigil, kejang perut, sulit bernafas keluar air liur, pupil mata mengecil, dan denyut nadi meningkat. Selanjutnya, keracunan yang sangat berat dapat mengakibatkan pingsan, kejang-kejang, bahkan bisa mengakibatkan kematian [13].

Dalam penerapan safety talk dan check ini, pemahaman petani akan bahaya pestisida masih rendah karena kurangnya perhatian petani dan Dinas Pertanian. Hal ini sejalan dengan penelitian Yuantari, yang menyatakan bahwa pola petani dalam aplikasi pestisida masih kurang mendapatkan perhatian dari Dinas Pertanian. Pengetahuan petani tentang pestisida sangat terbatas ditambah pola pikir yang kurang tepat dalam menggunakan pestisida. Dinas Pertanian masih memberi peningkatan hasil produksi dan sebaaiknya berintegrasi dengan instansi terkait lainnya. Pengetahuan yang minimal dalam penggunaan pestisida memberikan risiko bahaya bagi petani untuk mengalami keracunan pestisida [14,15].

Ketidakpedulian petani dalam menggunakan pestisida yang aman dan sehat dominan disebabkan karena belum tahunya petani akan bahaya dan risiko pestisida yang selama ini menjadi kesehariannya. Petani juga merasa kurang nyaman bila menggunakan pelindung diri karena membuat petani menjadi susah bergerak. Penggunaan pestisida juga dilakukan melebihi dosis yang dianjurkan disebabkan karena organisme pengganggu tanaman yang semakin resisten dengan jenis pestisida yang digunakan, sehingga petani berinisiatif sendiri melebihkan dosis takaran pestisida agar tercapai hasil panen (produksi) yang maksimal.

\section{Kesimpulan dan Saran}

Berdasarkan hasil penelitian yang dilakukan, petani di desa Sumber Mufakat menggunakan pestisida tidak sesuai prosedur karena tidak mengetahui dengan pasti pola penggunaan pestisida yang aman dan sehat. Penerapan metode safety talk dan check memiliki pengaruh yang signifikan terhadap awareness dan pengetahuan petani. Metode ini dapat berjalan sebagaimana mestinya dengan didukung adanya informasiinformasi terkait secara terus menerus antar kelompok tani dan diharapkan juga adanya dukungan dari instansi pemerintahan.

Untuk itu direkomendasikan untuk mengembangkan metode safety talk dan check ini dengan pembentukan komunitas peduli kesehatan petani yang bekerja sama dengan badan pengawas Kabupaten Karo sehingga dapat menyusun sanksi dan reward bagi desa yang mampu menggunakan pestisida yang aman dan sehat. 


\section{UCAPAN TERIMA KASIH}

Dalam kesempatan ini kami ucapkan terima kasih sebesar-besarnya pada masyarakat desa Sumber Mufakat yang telah berpartisipasi dalam kegiatan penelitian ini. Penelitian ini juga dapat terlaksana atas dukungan bapak Timur Tarigan selaku tokoh masyarakat dan para kader yang membantu dalam penerapan metode safety talk dan check yaitu Bapak Mesah, Bapak Harta dan Bapak Rudi, tim Rescue yang mendampingi dalam penerapan metode.Terima kasih kami ucapkan juga pada Lembaga Penelitian Universitas Sumatera Utara yang telah mendanai penelitian ini sebagai program TALENTA dari Tri Dharma Perguruan Tinggi sesuai dengan Kontrak Penelitian TALENTA Universitas Sumatera Utara Tahun Anggaran 2017 Nomor: 5338/UN5.1.R/PPM/2017 tanggal 22 Mei 2017.

\section{Daftar Pustaka}

[1] Undang-Undang Republik Indonesia Nomor 1 tahun 1970.

[2] Tarwaka. 2015. Keselamatan dan Kesehatan Kerja, manajemen dan Implementasi K3 di Tempat Kerja. Surakarta: Harapan Offset Surakarta.

[3] Kurniawidjaja, L. M. 2015. Teori dan Aplikasi Kesehatan Kerja. Jakarta: UI Press.

[4] Budiawan, A. R. 2013. Faktor Risiko Cholinesterase Rendah Pada Petani Bawang Merah. Jurnal Kesehatan Masyarakat KEMAS Volume 8(2) pp: 198-206, Semarang.

[5] Aktar, MD. W et. al. 2009. Impact of Pesticides Use in Agriculture; Their Benefits and Hazards; Interdisciplinary Toxicology Journal, Vol 2 (1); 1-12.

[6] Alavanja, M. CR, Hoppin, Jane, A, Kamel, Freya. 2009. Health effects of Chronic Pesticide Exposure; Cancer and Neurotoxicity Annual Review of Public Health, Volume 25; pp 155-97.

[7] Mahyuni, E. L. 2015. Faktor Risiko Dalam penggunaan Pestisida Terhadap Keluhan Kesehatan Pada Petani di Kecamatan Berastagi Kabupaten Karo 2014, Jurnal KESMAS, Volume 9, No. 1 pp 79-89.

[8] Mahyuni, E. L. 2016. Metode Penanggulangan Keracunan Pestisida di Desa Sumber Mufakat Kabanjahe Kabupaten Karo, Laporan Penelitian.

[9] Pratiknya, A. W. 2011. Dasar-dasar Metodologi Penelitian Kedokteran dan Kesehatan. Jakarta: PT. Raja Grafindo Persada.

[10] Faziah, E. G. Pengaruh Penggunaan Alat Pelindung Diri dengan Aktivitas Cholinesterase pada Teknisi Perusahaan Pest Control di DKI Jakarta tahun 2002. Diakses di http://lib.ui.ac.id/opac/themes/green/detail.jsp?id=73533\&lokasi=lokal.

[11] Samara, Diana, Bastaman, B, Jofizal, J. Duduk statis sebagai Faktor Risiko Terjadinya Nyeri Punggung Bawah pada Pekerja Perempuan. Universa Medicina, Vol 24, Nomor 2, April-Juni 2005.

[12] Pandit, G. S. 2006. Resiko pemakaian pestisida pada pertanian terhadap kesehatan manusia dan lingkungan. Lingkungan \& Pembangunan Wicaksana No. 15.

[13] Quijano, R dan Sarojeni V. R. 1999. Pestisida Berbahaya Bagi Kesehatan. Yayasan Duta Awan, Pesticide Action Network Asia and the Pasific, ISBN: 983-9381-11-3. Series : 983-9381-09-1.

[14] Yuantari, MG. C. 2012. Analisis Pola Petani Dalam Aplikasi Pestisida dan Dampaknya Bagi Kesehatan (Studi Kasus pada Petani Melon di Grobogan). Makalah Prosiding Seminar Nasional Rumusan Strategi Kesehatan dan Pertanian Dalam Percepatan Pengentasan Kemiskinan Menuju Tercapainya Target MDGs 2015, Politeknik Banjarnegara.

[15] Yuantari, MG. C. Budi, W, Henna R. S. 2013. Tingkat Pengetahuan Petani dalam Menggunakan Pestisida (Studi Kasus di Desa curut Kecamatan Penawangan Kabupaten Grobongan). Prosiding Seminar Nasional Pengelolaan Sumber Daya Alam dan Lingkungan. 